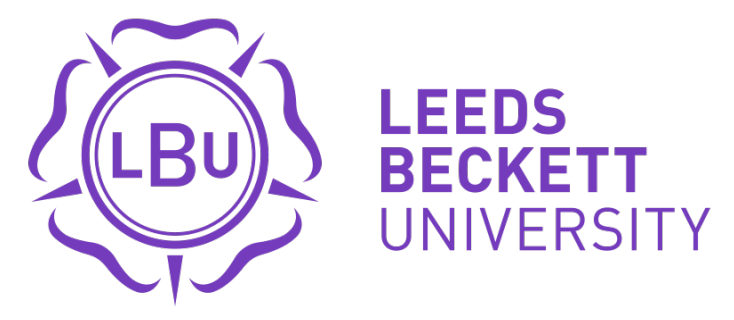

Citation:

Tee, JC and Till, K and Jones, BL (2019) Incidence and characteristics of injury in under-19 academy level rugby league match play: a single season prospective cohort study. Journal of Sports Sciences, 37 (10). pp. 1181-1188. ISSN 1466-447X DOI: https://doi.org/10.1080/02640414.2018.1547100

Link to Leeds Beckett Repository record:

https://eprints.leedsbeckett.ac.uk/id/eprint/5442/

Document Version:

Article (Accepted Version)

This is an Accepted Manuscript of an article published by Taylor \& Francis in Journal of Sports Sciences on 15 November 2018, available online: http://www.tandfonline.com/10.1080/02640414.2018.1547100

The aim of the Leeds Beckett Repository is to provide open access to our research, as required by funder policies and permitted by publishers and copyright law.

The Leeds Beckett repository holds a wide range of publications, each of which has been checked for copyright and the relevant embargo period has been applied by the Research Services team.

We operate on a standard take-down policy. If you are the author or publisher of an output and you would like it removed from the repository, please contact us and we will investigate on a case-by-case basis.

Each thesis in the repository has been cleared where necessary by the author for third party copyright. If you would like a thesis to be removed from the repository or believe there is an issue with copyright, please contact us on openaccess@leedsbeckett.ac.uk and we will investigate on a case-by-case basis. 


\section{Incidence and characteristics of injury in under-19 academy level}

rugby league match play: a single season prospective cohort study

Jason C. Tee, ${ }^{a}$ Kevin Till ${ }^{\mathrm{a}}$ and Ben Jones ${ }^{\mathrm{a}, \mathrm{b}, \mathrm{c}}$

${ }^{a}$ Institute for Sport, Physical Activity and Leisure, Leeds Beckett University, Leeds, West Yorkshire, United Kingdom; ${ }^{b}$ :The Rugby Football League, Leeds, England;

e:Yorkshire Carnegie Rugby Union club, Leeds, England

Address for correspondence:

Jason Cameron Tee,

Room 107a, Cavendish Hall,

Institute for Sport, Physical Activity and Leisure Centre for Sports Performance,

Headingley Campus,

Leeds Beckett University,

West Yorkshire,

LS6 3QS

Telephone: +44-113-812 7790

Email: j.c.tee@leedsbeckett.ac.uk

Word count: 3998 


\title{
Incidence and characteristics of injury in under-19 academy level rugby league match play: a single season prospective cohort study
}

\author{
Abstract: \\ Academy rugby league competition is an important step along the pathway to \\ professional status, but little is known about injury at this level of the game. The \\ aim of this research was to establish the nature, incidence and burden of injury in \\ English academy rugby league. Using an observational prospective cohort study \\ design, and a time-loss injury definition, the injury outcomes of three \\ professional rugby league academies were recorded during the 2017 season. A \\ total of 87 injuries occurred in 59 matches for an overall injury incidence of 85 \\ (95\%CI 67-103) injuries per 1000 hours played. The mean severity of injury was \\ $22 \pm 19$ days resulting in an overall injury burden of 1898 (95\%CI 1813-1983) \\ days lost per 1000 hours. The tackle event was the most common cause of injury \\ (77\% of all injuries). Forwards sustained a greater proportion of injuries than \\ backs (forwards 67\% vs. backs 33\% of injuries). Concussion (13 (6-20) per 1000 \\ hours) and ankle sprains (11 (4-17) per 1000 hours) were the most commonly \\ diagnosed injuries. The shoulder joint was the most commonly injured site (17 \\ (9-25) per 1000 hours). The incidence of injury for academy rugby league is \\ similar to senior professional rugby league.
}

Keywords: Injury, incidence, burden, team sport, position, tackle 


\section{Introduction}

Rugby League is an invasion sport characterised by frequent accelerations, decelerations, changes of direction and collisions between players (Johnston, Gabbett, \& Jenkins, 2014). The activity profile of the game is intermittent, with high-intensity periods of sprinting, accelerating and tackling interspersed with lower intensity periods of play that allow for active recovery (Johnston et al., 2014). Due to the physically intense nature of the sport and the frequency at which collisions occur, musculoskeletal injuries are common in rugby league (Hoskins, Pollard, Hough, \& Tully, 2006). A number of independent epidemiological studies of rugby league exist, however these are largely focused on the elite/professional levels of the game (Fitzpatrick, Naylor, Myler, \& Robertson, 2017; Gabbett, Ullah, \& Finch, 2012; Gissane, White, Kerr, Jennings, \& Jennings, 2003).

Rugby League is played world wide at junior and senior (adult) age groups and across competitive levels ranging from amateur to elite (Gabbett, King, \& Jenkins, 2008). Two professional leagues exist; the European Super League (ESL) in England and France, and the National Rugby League (NRL) in Australia and New Zealand. Within English Rugby League, the academy system represents an important step along the pathway to professional player status. Rugby league academies compete within an under-19-years-old competition structure, after which players progress to senior rugby league (Till, Jones, \& Geeson-Brown, 2016). Players are selected into academies from the age of 16 onwards, thus have a limited duration of time to sign full professional contracts. Players in the academy system play in a national league of 13 teams, receive professional coaching and strength and conditioning provision, and receive moderate remuneration for participation. 
Injury surveillance at the under 19 academy level is relatively sparse (Booth \& Orr, 2017; Estell, Shenstone, \& Barnsley, 1995; Gabbett 2008a; King \& Gabbett, 2009) and to date, no research has examined injury risk at academy level in England.

Furthermore, the synthesis of this existing research into a cohesive body of evidence is hampered by a number of methodological limitations including the inconsistent use of injury definitions (Hoskins et al., 2006; King, Gabbett, Gissane, \& Hodgson, 2009), single team studies (King et al., 2009), single season studies (Gabbett 2008a), differences in competition structures and differences in reporting method (survey vs. direct observation). As a result, injury incidence at under 19 academy level has been variably reported to be between 8 (Booth \& Orr, 2017) and 405 (Estell et al., 1995) medical attention injuries, or 2 (Booth \& Orr, 2017) to 78 (King \& Gabbett, 2009) missed match injuries per 1000 player hours (Table 1). It is unclear whether there is a difference in injury incidence between academy and elite professional levels of play (Hoskins et al., 2006). Moreover, the overall burden (total time lost to injury) (Bahr, Clarsen, \& Ekstrand, 2018) of injury at this level of play has not been established. Injury outcomes at academy level are important to consider because they may result in significant economic cost for the player and/or club (Gabbett 2001). In particular, the player's long-term career prospects (potential to become professional and potential to work in other physically demanding occupations) can be severely limited by injury at this level (Meir, McDonald, \& Russell, 1997). Accordingly, the aim of this research is to establish the incidence and burden of injury in academy rugby league and to describe the nature of injury in English Academy level rugby league. A secondary aim was to investigate whether risk factors (position, match quarter, injury mechanism) and patterns of injury (site and type) differ from those previously reported in senior professional competition. 


\section{Methods}

The study utilised an observational prospective cohort design. A convenience sample of five professional rugby league academies in the north of England were approached through the Rugby Football League (RFL; National Governing Body in England) and invited to take part in the study. Three teams accepted the invitation to participate, (the other two did not respond) representing $23 \%$ of the entire competition. All players $(n=81)$ from these teams were willing to participate and provided written informed consent for their injury data to be used for this study (mean age $17.8 \pm 0.7$ years, stature $180 \pm 6 \mathrm{~cm}$, body mass $88.0 \pm 11.3 \mathrm{~kg}$ ). Ethics approval for this research project was obtained from Leeds Beckett University, and consent for the use and publication of anonymised player injury data was obtained from the RFL.

Each academy nominated a physiotherapist in their employment to act as an “injury surveillance officer". All physiotherapists were qualified, registered with the Health and Care Professionals Council, and had at least two years experience in a professional team sport environment. The injury surveillance officers attended a twohour training workshop to ensure uniformity in the application of the injury definitions, as well as training on the injury recording system. The physiotherapists were remunerated for their time spent collecting injury data at a rate commensurate with the time required and their professional status. Data collection took place prospectively over the course of a single academy season (February to August 2017). Teams participated in a 20 game league competition that takes place over 28 weeks. Matches are scheduled on a weekly basis with byes (non-playing weeks) allocated intermittently throughout this period. One team discontinued data collection after 26 weeks (18 games). Following the league phase of the competition, a two week semi-final and final 
series takes place for the top four teams. One participating team played one game in this series. As such the data collection period was 29 weeks and 59 total matches.

Due to the inconsistent use of injury definitions in previous rugby league epidemiological research (Hoskins et al., 2006), a time-loss definition and reporting methods consistent with rugby union's 2007 International Rugby Board (IRB) consensus statement (Fuller et al., 2007) were adopted for this study (Table 1). The IRB consensus statement aligns with recommendations for the improvement of rugby league injury surveillance research (Hoskins et al., 2006; King et al., 2009), and allows for improved comparability with other sports codes. A similar approach was recently adopted by Fitzpatrick, Naylor, Myler and Roberston (2017) in their ESL epidemiological study. Only match time-loss injuries (an injury occurring during a match which resulted in a player being unable to take a full part in future rugby training or match play) were recorded for this study. Operationally, this required that the player was unable to take full part in normal rugby activities for $>24$ hours. Each individual injury was recorded on a bespoke data capture sheet that included the date of injury, date of return to practice or competition, and classification of the injury by body region (upper limb, lower limb, head and neck, trunk), body site (head/face, neck/cervical spine, sternum/ribs/upper back, abdomen, low back, sacrum/pelvis, shoulder/clavicle, upper arm, elbow, forearm, wrist, hand/finger/thumb, hip/groin, anterior thigh, posterior thigh, knee, lower leg/Achilles, ankle, foot/toe) and injury type (bone - fracture, other; joint/ligament - dislocation/subluxation, sprain/ligament, lesion of meniscus, cartilage or disc; muscle/tendon - muscle rupture/tear/strain/cramp, tendon injury/rupture/tendinopathy/ bursitis, haematoma/contusion/bruise; skin - laceration, abrasion; nervous system - concussion, brain structural injury, spinal cord compression or transection, nerve injury). In addition, information relating to the injury event was 
recorded; player position (back, forward), injury mechanism (contact, non-contact), injury event (tackle (further separated into tackler and tackled player roles), ruck involvement, open play collision, other) and game quarter (first, second, third or fourth). The definitions of each of these factors were in accordance with the IRB injury surveillance consensus statement (Fuller et al., 2007). All injuries were followed up until the end of the data collection period to determine an accurate injury severity and injury burden. At the end of this period, four players had not recovered from their injuries, and the respective physiotherapist for each team estimated a return from injury date based on their professional judgement. Match exposure time was calculated as -

Exposure time $=$ number of matches $\times$ match duration $\times$ number of players

No adjustment was made for players who left the field as a result of yellow and red cards. Injury severity was calculated as the total number of days elapsed from the day of injury until a player returned to full fitness, with full fitness being defined as "the player being able to take a full part in training activities typically planned for that day and available for match selection." (Fuller et al., 2007)

Two injury incidence metrics were calculated, the number of injuries per 1000 player-match hours and number of injuries per match, both with $95 \%$ confidence intervals (CIs). To allow for comparison with previous rugby league research, a surrogate equivalent of missed match injury incidence was calculated. To achieve this, all injuries $>7$ days in duration were considered 'missed match injuries'. As a result of scheduling (byes and occasional between match intervals of less than 7 days) this method may not reflect absolute missed match injury incidence. Injury severity was reported as the mean \pm standard deviation $(\mathrm{SD})$ number of days' players were unable to 
participate fully in training and match play. Injury burden was calculated as the total number of days lost to injury and then normalized to 1000 hours exposure (total days' absence per 1000 player-hours), with $95 \%$ confidence intervals. To determine the injury types that had the greatest effect on injury burden, and risk matrix was produced which plots injury incidence vs. severity (Bahr et al., 2018). Comparisons in injury incidence and severity were made for injury mechanism (contact vs. non-contact and tackler vs. ball carrier), match period (quarters 1 to 4 ) and position (backs vs. forwards). Incident rate ratios with $95 \%$ confidence intervals were calculated. Injury incidences were compared using 2-tailed Z tests (Kirkwood \& Sterne, 2003), and severities were compared using independent samples t-tests or one-way analysis of variance (ANOVA) as appropriate. Significance was set at $\mathrm{p}<0.05$.

Given the practical nature of this study, pairwise comparisons were also analysed using a magnitude-based inference (MBI) network to determine the likelihoods that the true value of the effects represent substantial change (Hopkins, Marshall, Batterham, \& Hanin, 2009). Incident rate ratios (IRRs) were calculated to compare the incidence of injuries at different sites or different mechanisms by expressing the injury incidences relative to one another. Meaningful differences were considered to be $>10 \%$ for incident risk ratios and $>0.2 \times$ between subject SD (based on Cohen's effect size (ES) principle) for comparisons of injury severity. The probability that the group differences were meaningful was rated as $<0.5 \%$, almost certainly not; 0.5-5\%, very unlikely; 5-25\%, unlikely; 25-75\%, possibly; 75-95\%, likely; 95-99.5\%, very likely; >99.5\%, almost certainly (Hopkins et al., 2009). Where the probabilities of a substantial positive and negative change were both greater than $5 \%$, the magnitude of change was described as unclear. 


\section{Results}

In total, 81 players participated in 59 matches (1022 player-match hours; backs $550 \mathrm{~h}$; forwards $472 \mathrm{~h}$ ) and 87 match injuries were recorded during this time. The injury incidence was 85 (67-103) injuries per 1000 hours, which equates to 1.5 (1.2-1.8) injuries per match (Table 2). The incidence of injuries $>7$ days in duration ("missed match" injuries) was 67 (51-82) per 1000 hours. These injuries resulted in 1940 player days lost to injury over the season (burden 1898 (1813-1983) days lost per 1000 hours). On average, the injury burden of match participation was $32 \pm 10$ days per team, and as a result teams typically had $4 \pm 1$ (approx. 15\%) squad members unavailable for selection each week due to injury.

\footnotetext{
*** Table 2 near here $* * *$
}

The lower limb was the most frequently injured body region, followed by the upper limb, then head and neck regions (Table 3). Joint/ligament injuries and muscle/tendon injuries occurred at a similar frequency (IRR 1.1, 95\%CI 0.7-1.6, unclear), but joint/ligament injures were likely more severe (joint/ligament $29 \pm 21$ vs. muscle/tendon $17 \pm 19$ days, likely medium) (Table 4 ). The greatest injury burden came from joint/ligament injuries (Table 4). The individual anatomical sites that resulted in the greatest burden were shoulder/clavicle, ankle, head/face) and knee. The injury types that resulted in the greatest injury burden were ligament sprains, tendon injury/rupture/tendinopathy/bursitis and concussion. Figure 1 presents the incidence and severity of the specific injuries that resulted in the greatest burden within this study. 
Contact injuries occurred more frequently than non-contact injuries (IRR 3.3, 2.1-5.3, p $<0.001$, contact most likely $\boldsymbol{\uparrow})$, but there was no difference in the mean severity of these injuries (Table 2). Contact injury mechanisms accounted for $77 \%$ of the total number of injuries sustained. The tackled player was twice as likely to be injured as the tackler (tackled 39 (27-51) vs. tackler 20 (11-28) injuries per 1000 hours; IRR 2.0, 95\%CI 1.2-3.1, $\mathrm{p}=0.009$ tackled very likely $\boldsymbol{\uparrow})$. When comparing injury mechanisms and injury type, upper limb injuries occurred more frequently to the tackler (tackler 15 (7-22) vs. tackled 6 (1-11) injuries per 1000 hours; IRR 2.5 95\%CI 0.8-7.6, tackler likely $\boldsymbol{\uparrow})$ while lower limb injuries occurred more frequently to the tackled player (tackler 2 (0-5) vs. tackled 18 (10-26) injuries per 1000 hours; IRR 9.0 95\%CI 0.2-328, tackled likely $\boldsymbol{\uparrow})$.

The injury incidence was two-times higher for forwards than for backs, but there was no difference in mean injury severity between positions (Table 2). Forwards were 1.6 times more likely to sustain a contact injury than backs, and 6.0 times more likely to sustain a non-contact injury (Table 2). Forwards spent 368 more days injured per 1000 hours exposure than backs, and $71 \%$ of this difference is a result of sustaining more non-contact injuries. Forwards had a significantly greater injury incidence for muscle/tendon injuries than backs (forwards 26 (17-36) vs. backs 9 (3-15) injuries per 1000 hours; IRR 2.9 95\%CI 1.4-6.1, forwards very likely $\boldsymbol{\uparrow}$ ). Similarly, joint/ligament injuries occurred at a likely higher frequency in forwards (forwards 20, (11-28) vs. backs 14, (7-21) injuries per 1000 hours; IRR 1.4 95\%CI 0.8-2.6, forwards likely $\boldsymbol{\uparrow}$ ). Forwards likely sustained upper limb injuries more frequently than backs (forwards 19 (10-27) vs. backs 3 (0-6) injuries per 1000 hours; IRR 6.3 95\%CI 0.2-250, forwards likely $\boldsymbol{\uparrow}$ ), and possibly sustained lower limb injuries more frequently than backs 
(forwards 21 (12-29) vs. backs 17 (9-25) injuries per 1000 hours; IRR 1.2 95\%CI 0.7 -

\section{2 , forwards possibly $\boldsymbol{\uparrow})$.}

Injury incidence in the second and fourth quarter of matches was likely to most likely greater than in the first and third quarters (Table 5). Injury severity was likely lower in final quarter vs. the second quarter of the match. Contact injury incidence was lowest in the first quarter, and highest in the second quarter of matches. Non-contact injury incidence was highest in the final quarter of matches. As a result, the highest injury burden was in the second quarter of matches.

\footnotetext{
****Table 5 near here****
}

\section{Discussion}

This study is the first to determine the incidence, severity, burden and nature of injuries in England's Academy Rugby League competition. The first main finding was that the incidence of injury in this group was 85 (67-103) injuries per 1000 hours. Injury incidence determined in this study was similar to that reported for professional ESL rugby league (Fitzpatrick et al., 2017) players (78 injuries per 1000 hours). When comparing across rugby codes, the injury incidence reported here was greater than English Academy rugby union (47 injuries per 1000 hours) (Palmer-Green et al., 2013), and similar to that of senior professional rugby union (81 injuries per 1000 hours) (Williams, Trewartha, Kemp, \& Stokes, 2013).

To allow for comparison with other rugby league injury research, injury incidence was also calculated according to the 'missed-match' definition. Using a missed match definition, the injury incidence (67 (51-82) missed match injuries per 1000 hours) was greater than that previously reported for junior (u16 to u19) (12 to 57 
injuries per 1000 hours) (Gabbett 2008a; Orr \& Cheng, 2016), amateur (27 injuries per 1000 hours) (Gabbett 2000), and professional teams (40 to 52 injuries per 1000 hours) (Gissane, Jennings, Kerr, \& White, 2002), but is similar to that reported for semiprofessional teams (68 to 78 injuries per 1000 hours)(Gabbett 2003; King \& Gabbett, 2009). Only one study has reported a higher injury incidence than that reported here, and this was for New Zealand junior (u16 to u18) teams (122 injuries per 1000 hours) (King 2006). Hoskins et al. (2006) previously demonstrated that there is no difference in injury incidence between sub-elite and elite levels of the game. The data presented here suggest that the injury rate in English Academy rugby league is similar to professional and semi-professional competition, and greater than for youth, and development competitions. This is in line with previous research in rugby that has shown the injury incidence in 'elite' junior competition to be similar to senior professional competition (Barden \& Stokes, 2018; Tee, Lebatie, Till, \& Jones, 2017).

The mean severity of injuries in English academy rugby league ( $22 \pm 19$ days), is similar what has been reported for professional ESL competition (24, 95\%CI 17-30 days) (Fitzpatrick et al., 2017), and as a result the injury burden across competitions is similar (professional 1872 vs. academy 1898 injured days per 1000 player-match hours).

The region, type and mechanism of injury were similar in this study compared with previous research (Fitzpatrick et al., 2017; Gabbett 2008a; Hoskins et al., 2006; King et al., 2009). Ligament sprains were the most frequent type of injury, and the lower limb was the most frequently injured body region. Injury occurred more frequently in the second and fourth quarter of matches suggesting that player fatigue may be a contributory risk factor. Non-contact injuries made a notably large contribution to injury burden $(46 \%)$ in the final quarter, while the highest contact injury 
incidence occurred at the end of the first half. Gabbett (2008b) demonstrated that tackle technique decreases in response to fatigue, which may explain the increased propensity for contact injuries late in the first half. The majority of injuries were as a result of tackle involvement, and the tackled player was injured more frequently than the tackler. Forwards were injured more frequently than backs, likely because of their more frequent ball carrying and tackler involvements (Gabbett et al., 2008; Johnston et al., 2014)

When individual injury sites and types were considered, it became apparent that the injury pattern in academy rugby league might be different from professional rugby. For example, in professional rugby league, the knee and hamstring are among the most frequently injured body sites (Fitzpatrick et al., 2017), while in this study the shoulder, head and ankle were the most frequently injured body sites. High frequencies of shoulder, and ankle injuries have previously been reported in youth rugby league (Gabbett 2008a; Orr \& Cheng, 2016). These findings indicate that injury risk profiles may differ between academy and professional levels of the game and that injury prevention programs likely need to differentiate between levels. Of concern was the fact that concussion occurred frequently within this study (13 injuries per 1000 hours), and at a rate higher than that reported for professional rugby league (5 injuries per 1000 hours) (Fitzpatrick et al., 2017) and professional rugby union (5 injuries per 1000 hours) (Cross, Kemp, Smith, Trewartha, \& Stokes, 2015). Links between head injuries and poor tackle technique are well established (Burger et al., 2016; Sobue et al., 2018), while it has also been demonstrated that well-developed physical qualities are protective against injury in contact sports (Collins et al., 2014; Gabbett et al., 2012). Recently research has demonstrated that improvement is strength and power qualities correlate with improvements in tackle ability in rugby league players (Speranza et al., 2016), and 
that reductions in these qualities during a playing season relate to reduced tackle ability (Speranza et al., 2017). This suggests that there may be an opportunity to influence injury outcomes by improving both physical preparation and tackle skill within this group, although further investigation into specific injury mechanisms is required.

A novel finding was that forwards were also more likely to suffer non-contact injuries than backs. It may be that because of the frequent and intense collisions that forwards are exposed to (Gabbett et al., 2008; Johnston et al., 2014), they fatigue more quickly than backs predisposing them to non-contact injury (Johnston, Gabbett, Seibold, \& Jenkins, 2014). This finding questions whether forward players have been sufficiently physically prepared for the demands of the game at academy level. Future research should aim to determine the physical characteristics, and training content and exposure of English academy level rugby union players, to determine whether there are associations between physical strength and fitness and injury outcomes. This information will assist in the development of effective injury prevention programs.

Rugby league epidemiological research suffers as the result of the use of variable injury definitions and collection methods (self-reported or observational) across studies (Hoskins et al., 2006; King et al., 2009) . Past research has relied largely on either a 'medical attention' or 'missed match' injury definitions (Gissane, Hodgson, \& Jennings, 2012). Medical attention injury rates are important for guiding health care management and the appointment and usage of primary care personnel in matches and training (Powell \& Dompier, 2004). However, in rugby league, players report that soreness is present throughout the entire season, even in "uninjured" players (Fletcher et al., 2016). If injury were to be defined by the presence of pain in this population, $100 \%$ of players would be injured $100 \%$ of the time. While this is clearly of concern, the prevalence of painful, but sub-clinical clinical conditions in rugby league makes the use 
of the 'medical attention' injury definition problematic. The missed match injury definition is problematic when matches do not follow a regular weekly schedule, resulting in increased or decreasing injury incidence if matches are played more or less frequently. Further to these problems, neither method accurately calculates the injury severity (duration of time that a player is injured for) making it difficult to establish which injuries lead to the greatest loss of player time, as opposed to those injuries that occur most frequently (Drawer \& Fuller, 2002). Calculating total time lost (injury burden) makes team injury outcomes relatable to team performance (Williams et al., 2015), and allows for prioritization of the injury types than need to be addressed through injury prevention plans. For these reasons, following the recommendations of Hoskins (2006), and in alignment with the work of Fitzpatrick et al. (2017), a time-loss definition was applied to this study. This has allowed for the accurate quantification of total time lost to injury within this study and the identification of injury types that present the greatest risk in this population. It is hoped that the methods employed by these two studies will become the benchmark for future epidemiological research in rugby league.

With regard to limitations of this study, it is recognized that the cohort represented in this study only comprises a quarter (23\%) of the total English academy player population, and that this study would be improved by a league wide injury surveillance program that takes place over a number of seasons. In addition, the present analysis is restricted to match-related rugby league exposure, and does not account for injuries that occurred during training, and did not account for injuries that occurred prior to the commencement of the study that may have influenced the risk of injury within the data collection period. 
In conclusion, this study found that the incidence of match injury in English academy rugby league is higher than that reported in previous studies of youth rugby league and is similar to that reported for senior professional and semi-professional players. The injury types and locations were similar to that reported in previous epidemiological studies of junior and senior rugby league. It was notable that the burden concussion and shoulder injuries in this population is greater than in senior professional rugby league, indicating that injury prevention interventions may need to be specific to the competition within which they are implemented. Further investigation into the mechanism of injury (particularly tackle injuries, which are the most prevalent), preventative interventions are required.

\section{References}

Bahr, R., Clarsen, B., \& Ekstrand, J. (2018). Why we should focus on the burden of injuries and illnesses, not just their incidence. British Journal of Sports Medicine, 52(17), 1018-1021

Barden, C., \& Stokes, K. (2018). Epidemiology of injury in elite English schoolboy rugby union: A 3-year study comparing different competitions. Journal of Athletic Training. Advance online publication [doi:10.4085/1062-6050-311-16]

Booth, M., \& Orr, R. (2017). Time-loss injuries in sub-elite and emerging rugby league players. Journal of Sports Science \& Medicine, 16(2), 295-301.

Burger, N., Lambert, M. I., Viljoen, W., Brown, J. C., Readhead, C., \& Hendricks, S. (2016). Tackle technique and tackle-related injuries in high-level South African rugby union under-18 players: Real-match video analysis. British Journal of Sports Medicine. 50(15), 932-938

Collins, C. L., Fletcher, E. N., Fields, S. K., Kluchurosky, L., Rohrkemper, M. K., Comstock, R. D., \& Cantu, R. C. (2014). Neck strength: A protective factor reducing risk for concussion in high school sports. The Journal of Primary Prevention, 35(5), 309-19.

Cross, M., Kemp, S., Smith, A., Trewartha, G., \& Stokes, K. (2015). Professional rugby union players have a $60 \%$ greater risk of time loss injury after concussion: A 2- 
season prospective study of clinical outcomes. British Journal of Sports Medicine, 50(15), 926-31.

Drawer, S., \& Fuller, C. W. (2002). Evaluating the level of injury in English professional football using a risk based assessment process. British Journal of Sports Medicine, 36(6), 446-51.

Estell, J., Shenstone, B., \& Barnsley, L. (1995). Frequency of injuries in different agegroups in an elite rugby league club. Australian Journal of Science and Medicine in Sport, 27(4), 95-7.

Fitzpatrick, A. C., Naylor, A. S., Myler, P., \& Robertson, C. (2017). A three-year epidemiological prospective cohort study of rugby league match injuries from the European Super League. Journal of Science and Medicine in Sport, 21(2), 160-165.

Fletcher, B. D., Twist, C., Haigh, J. D., Brewer, C., Morton, J. P., \& Close, G. L. (2016). Season-long increases in perceived muscle soreness in professional rugby league players: Role of player position, match characteristics and playing surface. Journal of Sports Sciences, 34(11), 1067-72.

Fuller, C. W., Molloy, M. G., Bagate, C., Bahr, R., Brooks, J. H., Donson, H., . . . Wiley, P. (2007). Consensus statement on injury definitions and data collection procedures for studies of injuries in rugby union. British Journal of Sports Medicine, 41(5), 328-31.

Gabbett, T. J. (2000). Incidence, site, and nature of injuries in amateur rugby league over three consecutive seasons. British Journal of Sports Medicine, 34(2), 98103.

Gabbett, T. J. (2001). Severity and cost of injuries in amateur rugby league: A case study. Journal of Sports Sciences, 19(5), 341-7.

Gabbett, T. J. (2003). Incidence of injury in semi-professional rugby league players. British Journal of Sports Medicine, 37(1), 36-43;

Gabbett, T. J. (2008a). Incidence of injury in junior rugby league players over four competitive seasons. Journal of Science and Medicine in Sport, 11(3), 323-8.

Gabbett, T.J. (2008b). Influence of fatigue on tackling technique in rugby league players. Journal of Strength and Conditioning Research, 22(2), 625-32

Gabbett, T. J., King, T., \& Jenkins, D. (2008). Applied physiology of rugby league. Sports Medicine, 38(2), 119-38. 
Gabbett, T. J., Ullah, S., \& Finch, C. F. (2012). Identifying risk factors for contact injury in professional rugby league players--application of a frailty model for recurrent injury. Journal of Science and Medicine in Sport, 15(6), 496-504.

Gissane, C., Jennings, D., Kerr, K., \& White, J. A. (2002). A pooled data analysis of injury incidence in rugby league football. Sports Medicine, 32(3), 211-6.

Gissane, C., White, J., Kerr, K., Jennings, S., \& Jennings, D. (2003). Health and safety implications of injury in professional rugby league football. Occupational Medicine, 53(8), 512-7.

Gissane, C., Hodgson, L., \& Jennings, D. (2012). Time-loss injuries versus non-timeloss injuries in the first team rugby league football: A pooled data analysis. Clinical Journal of Sport Medicine, 22(5), 414-7.

Hopkins, W. G., Marshall, S. W., Batterham, A. M., \& Hanin, J. (2009). Progressive statistics for studies in sports medicine and exercise science. Medicine and Science in Sports and Exercise, 41(1), 3-13.

Hoskins, W., Pollard, H., Hough, K., \& Tully, C. (2006). Injury in rugby league. Journal of Science and Medicine in Sport 9(1-2), 46-56.

Johnston, R. D., Gabbett, T. J., \& Jenkins, D. G. (2014). Applied sport science of rugby league. Sports Medicine, 44(8), 1087-100.

Johnston, R. D., Gabbett, T. J., Seibold, A. J., \& Jenkins, D. G. (2014). Influence of physical contact on neuromuscular fatigue and markers of muscle damage following small-sided games. Journal of Science and Medicine in Sport, 17(5), 535-40.

King, D. (2006). Incidence of injuries in the 2005 New Zealand national junior rugby league competition. New Zealand Journal of Sports Medicine, 34(1), 21-27.

King, D. A., Gabbett, T. J., Gissane, C., \& Hodgson, L. (2009). Epidemiological studies of injuries in rugby league: Suggestions for definitions, data collection and reporting methods. Journal of Science and Medicine in Sport, 12(1), 12-9.

King, D. G., \& Gabbett, T. J. (2009). Injuries in the New Zealand semi-professional rugby league competition. New Zealand Journal of Sports Medicine, 36(1), 615.

Kirkwood, B. R., \& Sterne, J. A. C. (2003). Essential medical statistics (2nd ed.). Malden, MA: Blackwell Science. 
Meir, R. A., McDonald, K. N., \& Russell, R. (1997) Injury consequences from participation in professional rugby league: a preliminary investigation. British Journal of Sports Medicine, 31(2), 132-4.

Orr, R., \& Cheng, H. L. (2016). Incidence and characteristics of injuries in elite Australian junior rugby league players. Journal of Science and Medicine in Sport, 19(3), 212-7.

Palmer-Green, D. S., Stokes, K. A., Fuller, C. W., England, M., Kemp, S. P., \& Trewartha, G. (2013). Match injuries in English youth academy and schools rugby union: An epidemiological study. The American Journal of Sports Medicine, 41(4), 749-55.

Powell, J. W., \& Dompier, T. P. (2004). Analysis of injury rates and treatment patterns for time-loss and non-time-loss injuries among collegiate student-athletes. Journal of Athletic Training, 39(1), 56-70.

Sobue, S., Kawasaki, T., Hasegawa, Y., Shiota, Y., Ota, C., Yoneda, T., . . Kaneko, K. (2018). Tackler's head position relative to the ball carrier is highly correlated with head and neck injuries in rugby. British Journal of Sports Medicine, 52(6), 353-358.

Speranza, M.J.A., Gabbett, T.J., Johnston, R.D., \& Sheppard, J.M. (2016). Effect of Strength and Power Training on Tackling Ability in Semiprofessional Rugby League Players. Journal of Strength and Conditioning Research, 30(2), 336-43.

Speranza, M.J.A., Gabbett, T.J., Greene, D.A., Johnston, R.D., \& Sheppard, J.M. (2017). Changes in Rugby League Tackling Ability During a Competitive Season: The Relationship With Strength and Power Qualities. Journal of Strength and Conditioning Research, 31(12), 3311-3318.

Tee, J. C., Lebatie, F., Till, K., \& Jones, B. (2017). Injury incidence and characteristics in South African school first team rugby: A case study. South African Journal of Sports Medicine, 29(1), 1-7.

Till, K., Jones, B., \& Geeson-Brown, T. (2016). Do physical qualities influence the attainment of professional status within elite 16-19 year old rugby league players? Journal of Science and Medicine in Sport, 19(7), 585-9.

Williams, S., Trewartha, G., Kemp, S., \& Stokes, K. (2013). A meta-analysis of injuries in senior men's professional rugby union. Sports Medicine, 43(10), 1043-55.

Williams, S., Trewartha, G., Kemp, S. P., Brooks, J. H., Fuller, C. W., Taylor, A. E., . . Stokes, K. A. (2015). Time loss injuries compromise team success in elite rugby 
union: A 7-year prospective study. British Journal of Sports Medicine, 50(11), 651-6. 


\section{Tables}

Table 1. Injury definitions used in previous youth rugby league epidemiological research.

\begin{tabular}{|c|c|c|c|}
\hline Authors & $\begin{array}{l}\text { Definition } \\
\text { type }\end{array}$ & Definition & $\begin{array}{l}\text { Reported } \\
\text { incidence }\end{array}$ \\
\hline $\begin{array}{l}\text { Booth \& } \\
\text { Orr, } 2017\end{array}$ & $\begin{array}{l}\text { Medical } \\
\text { attention }\end{array}$ & $\begin{array}{l}\text { "any physical or medical condition that occurs } \\
\text { during participation in rugby league match or } \\
\text { training activities that requires medical } \\
\text { treatment or results in a missed match or } \\
\text { training participation" }\end{array}$ & $\begin{array}{l}7.9 \text { injuries } \\
\text { per } 1000 \\
\text { hours* }\end{array}$ \\
\hline $\begin{array}{l}\text { Booth \& } \\
\text { Orr, } 2017\end{array}$ & $\begin{array}{l}\text { Missed } \\
\text { match }\end{array}$ & $\begin{array}{l}\text { "injury was defined as any physical pain or } \\
\text { impairment sustained during a match or } \\
\text { training that resulted in players subsequently } \\
\text { missing a match" }\end{array}$ & $\begin{array}{l}1.8 \text { injuries } \\
\text { per } 1000 \\
\text { hours* }\end{array}$ \\
\hline $\begin{array}{l}\text { King \& } \\
\text { Gabbett, } \\
2009\end{array}$ & $\begin{array}{l}\text { Medical } \\
\text { attention }\end{array}$ & $\begin{array}{l}\text { "any pain or disability suffered by a player } \\
\text { during a match that required advice and/or } \\
\text { treatment" }\end{array}$ & $\begin{array}{l}115 \text { injuries } \\
\text { per } 1000 \\
\text { hours* }\end{array}$ \\
\hline $\begin{array}{l}\text { King \& } \\
\text { Gabbett, } \\
2009\end{array}$ & $\begin{array}{l}\text { Missed } \\
\text { match }\end{array}$ & $\begin{array}{l}\text { As above, but "also classified according to the } \\
\text { number of matches missed". }\end{array}$ & $\begin{array}{l}78 \text { injuries } \\
\text { per } 1000 \\
\text { hours* }\end{array}$ \\
\hline $\begin{array}{l}\text { Gabbett, } \\
2008 \mathrm{a}\end{array}$ & $\begin{array}{l}\text { Missed } \\
\text { match }\end{array}$ & $\begin{array}{l}\text { "an injury was defined as any pain or disability } \\
\text { suffered by a player during a match that } \\
\text { resulted in the player missing a subsequent } \\
\text { match." }\end{array}$ & $\begin{array}{l}56.8(42.6- \\
70.9) \\
\text { injuries per } \\
1000 \text { hours }\end{array}$ \\
\hline \multirow[t]{2}{*}{$\begin{array}{l}\text { Estell et } \\
\text { al., } 1996\end{array}$} & $\begin{array}{l}\text { Medical } \\
\text { attention }\end{array}$ & $\begin{array}{l}\text { "Pain, discomfort or disability arising during, } \\
\text { or immediately after, and as a result of, playing } \\
\text { in a rugby league match" }\end{array}$ & $\begin{array}{l}405 \text { injuries } \\
\text { per } 1000 \\
\text { hours* }\end{array}$ \\
\hline & $\begin{array}{l}\text { Missed } \\
\text { match }\end{array}$ & $\begin{array}{l}\text { "Pain, discomfort or disability arising during, } \\
\text { or immediately after, and as a result of, playing } \\
\text { in a rugby league match that resulted in a } \\
\text { missed match" }\end{array}$ & $\begin{array}{l}28 \text { injuries } \\
\text { per } 1000 \\
\text { hours* }\end{array}$ \\
\hline This study & Time loss & $\begin{array}{l}\text { "Any physical complaint, that was sustained by } \\
\text { a player during a rugby match that results in a } \\
\text { player being unable to take a full part in future } \\
\text { rugby training or match play" (Fuller et al., } \\
2007 \text { ) }\end{array}$ & $\begin{array}{l}85(67-103) \\
\text { injuries per } \\
1000 \text { match } \\
\text { hours }\end{array}$ \\
\hline
\end{tabular}

* No confidence intervals provided. 
Table 2. Injury incidence, severity and burden of Academy level rugby league players in England presented in total, and differentiated by position (backs vs. forwards)

\begin{tabular}{|c|c|c|c|c|}
\hline & All players & Backs & Forwards & $\begin{array}{c}\text { IRR, } 95 \% \mathrm{CI} \\
M B I\end{array}$ \\
\hline Exposure (h) & 1022 & 550 & 472 & \\
\hline Injuries (n) & 87 & 31 & 56 & \\
\hline - Contact & $67(77 \%)$ & $28(90 \%)$ & $39(70 \%)$ & \\
\hline - Non-contact & $20(23 \%)$ & $3(10 \%)$ & $17(30 \%)$ & \\
\hline Injury incidence & $85(67-103)$ & $56(37-76)$ & $119(88-150)$ & $\begin{array}{c}2.1(1.5-3.1)^{*} \\
\text { Forwards most likely }\end{array}$ \\
\hline - Contact & $66(50-81)$ & $51(32-70)$ & $83(57-109)$ & $\begin{array}{c}1.6(1.1-2.4)^{*} \\
\text { Forwards likely } \boldsymbol{\uparrow}\end{array}$ \\
\hline - Non-contact & $20(11-28)$ & $6(0-12)$ & $36(19-53)$ & $\begin{array}{c}6.0(0.3-140.6)^{*} \\
\text { Forwards likely } \uparrow\end{array}$ \\
\hline Severity (days) & $22 \pm 19$ & $25 \pm 19$ & $21 \pm 20$ & Unclear \\
\hline - Contact & $22 \pm 19$ & $25 \pm 19$ & $21 \pm 19$ & Unclear \\
\hline - Non-contact & $21 \pm 21$ & $25 \pm 17$ & $20 \pm 22$ & Unclear \\
\hline Burden & $\begin{array}{c}1898 \\
(1838-1983)\end{array}$ & $\begin{array}{c}765 \\
(711-819)\end{array}$ & $\begin{array}{c}1133 \\
(1067-1199)\end{array}$ & \\
\hline - Contact & $\begin{array}{c}1492 \\
(1416-1568)\end{array}$ & $\begin{array}{c}692 \\
(640-744)\end{array}$ & $\begin{array}{c}800 \\
(745-855)\end{array}$ & \\
\hline - Non-contact & $\begin{array}{c}406 \\
(367-446)\end{array}$ & $\begin{array}{c}73 \\
(56-90)\end{array}$ & $\begin{array}{c}333 \\
(297-369)\end{array}$ & \\
\hline
\end{tabular}

Injury incidence is injuries per 1000 hours of match play $(95 \% \mathrm{CI})$, severity is the mean time lost to injury (mean \pm SD). Burden it the number of days lost per 1000 hours of match play $(95 \% \mathrm{CI}) \mathrm{IRR}$ is incidence rate ratio backs vs. forwards. * indicates significant difference backs vs. forwards $(\mathrm{p}<0.05)$. MBI indicate magnitude based inference 
Table 3. Academy rugby league injury sites expressed according to incidence, severity and burden.

\begin{tabular}{|c|c|c|c|}
\hline Site & Incidence & Severity & Burden \\
\hline HEAD AND NECK & $14(7-21)$ & $23 \pm 13$ & $318(283-353)$ \\
\hline Head/Face & $14(7-21)$ & $23 \pm 13$ & $318(283-353)$ \\
\hline Neck/Cervical Spine & - & - & - \\
\hline TRUNK & $7(2-12)$ & $12 \pm 12$ & $80(63-98)$ \\
\hline Sternum/Ribs/Upper & $3(0-6)$ & $6 \pm 3$ & $17(9-25)$ \\
\hline \multicolumn{4}{|l|}{ Back } \\
\hline Abdomen & - & - & - \\
\hline Low Back & $4(0-8)$ & $16 \pm 14$ & $63(47-79)$ \\
\hline Sacrum/Pelvis & - & - & - \\
\hline UPPER LIMB & $22(13-31)$ & $26 \pm 24$ & $551(505-597)$ \\
\hline Shoulder/Clavicle & $17(9-25)$ & $32 \pm 24$ & $525(480-525)$ \\
\hline Upper Arm & - & - & - \\
\hline Elbow & $2(0-5)$ & $6 \pm 1$ & $12(5-19)$ \\
\hline Forearm & - & - & - \\
\hline Wrist & $3(0-6)$ & $5 \pm 4$ & $14(7-21)$ \\
\hline Hand/Finger/ Thumb & - & - & - \\
\hline LOWER LIMB & $42(30-59)$ & $22 \pm 20$ & $950(890-1010)$ \\
\hline Hip/Groin & $7(2-12)$ & $17 \pm 14$ & $119(98-140)$ \\
\hline Anterior Thigh & $4(0-8)$ & $10 \pm 10$ & $39(29-51)$ \\
\hline Posterior Thigh & $2(0-5)$ & $15 \pm 11$ & $29(18-40)$ \\
\hline Knee & $13(6-20)$ & $21 \pm 16$ & $261(229-293)$ \\
\hline Lower Leg/ Achilles & $6(1-11)$ & $25 \pm 35$ & $146(122-170)$ \\
\hline Ankle & $11(4-17)$ & $30 \pm 20$ & $322(287-357)$ \\
\hline Foot/Toe & $1(0-3)$ & $34 \pm 0$ & $33(22-44)$ \\
\hline
\end{tabular}

Incidence is injuries per 1000 hours of match play $(95 \% \mathrm{CI})$, severity is the mean time lost to injury (mean $\pm \mathrm{SD}$ ). Burden it the number of days lost per 1000 hours of match play (95\%CI). - indicates that no injuries occurred within this category. 
Table 4. Academy rugby league injury types expressed according to incidence, severity and burden.

\begin{tabular}{|c|c|c|c|}
\hline Site & Incidence & Severity & Burden \\
\hline BONE INJURIES & $3(0-6)$ & $7 \pm 5$ & $21(12-30)$ \\
\hline Fracture & - & - & - \\
\hline Other & $3(0-6)$ & $7 \pm 5$ & $21(12-30)$ \\
\hline JOINT/LIGAMENT & $33(22-46)$ & $29 \pm 21$ & 958 (897-1019) \\
\hline \multicolumn{4}{|l|}{ INJURIES } \\
\hline Dislocation/Subluxation & $3(0-6)$ & $41 \pm 29$ & $121(99-143)$ \\
\hline Sprain/Ligament Injury & $24(14-33)$ & $24 \pm 17$ & $571(524-571)$ \\
\hline $\begin{array}{l}\text { Lesion of meniscus, } \\
\text { cartilage or disc. }\end{array}$ & $7(2-12)$ & $39 \pm 28$ & $265(233-297)$ \\
\hline MUSCLE/TENDON & $35(24-47)$ & $17 \pm 19$ & $602(554-650)$ \\
\hline \multicolumn{4}{|l|}{ INJURIES } \\
\hline $\begin{array}{l}\text { Muscle rupture/Tear/ } \\
\text { Strain/Cramp }\end{array}$ & $12(5-18)$ & $11 \pm 9$ & $129(107-151)$ \\
\hline $\begin{array}{l}\text { Tendon injury/Rupture/ } \\
\text { Tendinopathy/Bursitis }\end{array}$ & $15(7-22)$ & $25 \pm 25$ & $370(332-408)$ \\
\hline $\begin{array}{l}\text { Haematoma/Contusion/ } \\
\text { Bruise }\end{array}$ & $9(3-15)$ & $12 \pm 11$ & $103(83-123)$ \\
\hline SKIN INJURIES & $1(0-3)$ & 2 & $2(0-5)$ \\
\hline Abrasion & - & - & - \\
\hline Laceration & $1(0-3)$ & 2 & $2(0-5)$ \\
\hline NERVOUS SYSTEM & $13(6-20)$ & $25 \pm 12$ & $316(281-351)$ \\
\hline \multicolumn{4}{|l|}{ INJURIES } \\
\hline Brain - Concussion & $13(6-20)$ & $25 \pm 12$ & $316(281-351)$ \\
\hline Brain - Structural & - & - & - \\
\hline $\begin{array}{l}\text { Spinal cord - } \\
\text { Compression/Transection }\end{array}$ & - & - & - \\
\hline Nerve injury & - & - & - \\
\hline
\end{tabular}

Incidence is injuries per 1000 hours of match play (95\% CI), severity is the mean time lost to injury (mean $\pm \mathrm{SD}$ ). Burden it the number of days lost per 1000 hours of match play $(95 \% \mathrm{CI})$. - indicates that no injuries occurred within this category. 
2 Table 5. Comparison of injury incidence, severity and burden across match periods.

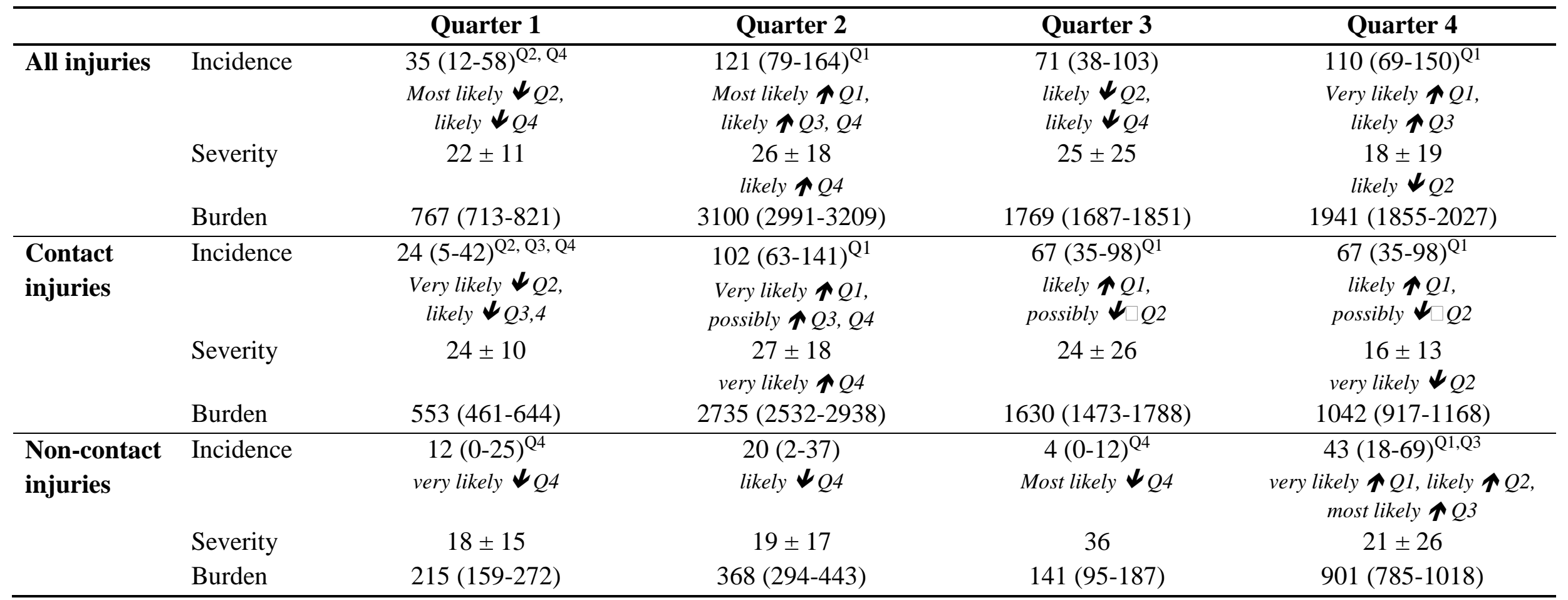

Incidence is injuries per 1000 hours of match play $(95 \% \mathrm{CI})$, severity is the mean time lost to injury (mean \pm SD). Burden it the number of days lost per 1000 hours of match play $(95 \% \mathrm{CI}) .{ }^{\mathrm{Q} 1, \mathrm{Q} 2, \mathrm{Q} 3}$ and ${ }^{\mathrm{Q} 4}$ indicate significant differences from quarter 1, 2, 3 and 4 respectively (p<0.05). Magnitude based inference presented in italics below 


\section{Figure captions}

Figure 1. Injury risk matrix (incidence vs. severity) of the ten injury types that resulted in the greatest injury burden for academy rugby league players. Value in brackets is the total injury burden in days. 